\section{Journal of Computer Networks, Architecture and High Performance Computing}

Volume 3, Number 2, July 2021

https://doi.org/10.47709/cnahpc.v3i2.950
Submitted : 18 April 2021

Accepted : 27 April 2021

Published : 16 July 2021

\title{
Implementation of Water Conditions in Soil with Artificial Neural Network Method using Backpropagation
}

\author{
Toppan Sintio ${ }^{1)}$, Steven $^{2)}$, Yennimar ${ }^{3)}$ \\ 1)2)3) Universitas Prima Indonesia, Indonesia \\ ${ }^{1}$ toppansintio@yahoo.com, ${ }^{2}$ stevencai@gmail.com
}

\begin{abstract}
In agriculture and plantations, the land is an important thing, but sometimes the soil needs to be measured for its fertility, so measuring instruments are used. In this study, the authors tried to collect data for measuring using the Backpropagation method to determine the prediction of fertility in the soil. The backpropagation method is used to predict and also Backpropagation is a Neural Network algorithm. In using this method, input is a sensor that will take data in the form of soil moisture, $\mathrm{pH}$ when wet, and $\mathrm{pH}$ when dry, followed by this method which processes the data to be generated. The results of research with the Backpropagation algorithm get $80 \%$ accuracy of the 10 test data used for test results. The results tested initially were not as expected but with several trials, it was almost as expected but needed to be further developed. With the hope that there are people who can develop better for more knowledge and hopefully it can be useful for more. The suggestion in this is for readers who want to develop their suggestions to collect more data from this research to get more satisfying results. If the data is not more efficient, more efficient or accurate methods or means of data collection are expected to be used.
\end{abstract}

Keywords: Backpropagation, Neural Network, Prediction, pH, Soil Fertility.

\section{INTRODUCTION}

Water content is the amount of water contained in an object such as water in the soil which can also be called soil moisture, rocks containing water, agricultural materials, and so on which contain water. Moisture content is widely used in scientific and engineering fields and is usually expressed in the form of a ratio from a value of 0 (total dryness or no moisture content) to a saturated water value where all the pores are filled with water. The assessments can be volumetric or gravimetric (mass or weight in liters), and in the form of a wet basis and a dry basis.

$\mathrm{PH}$ (power of hydrogen) is the degree of acidity used to express the level of acidity or alkalinity of a solution. It is usually defined as a cologarithm of the activity of the dissolved hydrogen $(\mathrm{H}+)$ ion. The coefficient of hydrogen ion activity cannot be measured experimentally, so its value is based on theoretical calculations. The $\mathrm{PH}$ scale is not an absolute scale or a non-absolute scale. This $\mathrm{pH}$ is relative to a set of standard solutions whose $\mathrm{PH}$ has been determined based on international agreements.

$\mathrm{PH}$ or power of hydrogen is very much needed in agriculture, cultivation, and plant sellers to see soil fertility and water content is also needed so that plants do not lack water. At $\mathrm{pH}$ and moisture content to assess the soil is fertile or deficient in nutrients. And the PH tool is also very expensive and the PH meter can also pass the spices but it is not accurate just to show this is acidic and this is alkaline. The water content here is the water content in the soil which can be seen that the soil is wet but it could be a lack of water. To solve these problems, a process is carried out to make goods or services that can facilitate the measurement. In solving this problem the researcher wants to use a decision-maker with the backpropagation algorithm.

\section{LITERATURE REVIEW}

Imelda Asih Rohani Simbolon, Fikri Yatussaada, and Anjar Wanto conducted a study on the application of the backpropagation algorithm in predicting the percentage of illiterate people in Indonesia. In their research, they used data from the Central Bureau of Statistics as data for research using ages from 15 to 44 years to be processed with backpropagation. The results they got from the study were accurate with $91 \%$ accuracy from 34 data (Imelda Simolon, Asih Rohani, and Fikri Yatussaada, and Anjar Wanto, 2018).

* Corresponding author

This is an Creative Commons License This work is licensed under a Creative

Commons Attribution-NoDerivatives 4.0 International License. 


\section{Journal of Computer Networks, Architecture and High Performance Computing}

Volume 3, Number 2, July 2021

https://doi.org/10.47709/cnahpc.v3i2.950
Submitted : 18 April 2021

Accepted : 27 April 2021

Published : 16 July 2021

Muhammad Dedek Yalidhan and Muhammad Faisal Amin researched artificial neural networks using backpropagation to predict student graduation outcomes. In their research, they used a sample dataset of 318 samples of $70 \%$ of the data as training and the rest for testing and getting accurate results with an accuracy of $98.97 \%$ (Muhammad Dedek Yalidhan, and Muhammad Faisal Amin, 2018)

Anjar Wanto researched prediction optimization with the backpropagation algorithm and conjugate gradient Beale-Powell restarts. In Anjar Warto's research, predictions on the consumer index price based on health group with city hall statistics. In the research process, Anjar Wanto used the backpropagation algorithm to calculate groupings of data and an algorithm to calculate errors. The results of Anjar Wanto's research show that the results are almost accurate when compared (Wanto, 2018)

Tri Ferga Prasetyo, Abghi Firas Isdiana, and Harun Sujadi researched the implementation of a water content detection tool in food based on the internet of things. In their research, they connected the device to Android. The objects they studied were foodstuffs such as tomatoes, watermelons, rice, and bananas. The android connected device will light green light if the water content is high and the LCD screen will display the percentage of the water content (Tri Fadhel Prasetyo, Abghi Firas Isdianab, and Harun Sujadi, 2019).

Fadhel Akhmad Hizham, Yanuar Nurdiansyah, Diksy Media Firmansyah researched the implementation of the backpropagation neural network (BNN) method in the classification system for punctuality of student graduation. In their research, they used data mining from the University of Jember using the ip value as data to be processed using backpropagation. The results of these studies get accurate results with an accuracy of $98.72 \%$ (Fadhel Akhmad Hizham, Yanuar Nurdiansyah, and Diksy Media Firmansyah, 2018).

Karamina, H. W. Fikrinda. AT Murti conducted a study on the complexity of the effect of temperature and soil moisture on the $\mathrm{pH}$ value of soil in the guava plantation of the critical variety (Psidium Guajava 1.) bumiaji, Batu City. The Karamina study, it examined soil moisture in guava trees which used trees of different ages (Karamina, and Fikirinda W. H., 2017).

Oktari Hermita, Sri Rahayu Utami, and Syahrul Kurniawan researched soil chemical properties in various land uses in UBForest. In their research, they calculated the value of CEC or cation exchange capacity in soil with chemical elements to see how much of the content can be absorbed in plants.

In this study, the authors wanted to collect data in the form of soil moisture to make it easier for farmers, planters, and fields related to retrieving data. The data that the writer will use are soil moisture, dry and wet soil ph. The data is taken to decide whether the land is fertile for growing plants or not fertile, if it is not fertile here it becomes easier for users to provide nutrients to the land (Putri, Oktari Hermita, Sri Rahayu utami, and Syahrul Kurniawan., 2019)

\section{METHOD}

This study using the Backpropagation method which is an artificial neural network that uses input taken using a sensor to obtain the input value. In the next process, the input can be continued to the Backpropagation method which uses 2 hidden layers and produces 1 output to be the result in the process.

In the data retrieval process, 3 sensors are used in the form of an ADC sensor, a soil V2 sensor, and a $\mathrm{pH}$ detection sensor. In the ADC sensor, its function is to take ph data when it is dry, then the soil V2 sensor is to take the value of soil moisture, and finally, the $\mathrm{pH}$ sensor detection is to takes a value on the $\mathrm{pH}$ of the soil when wet. 


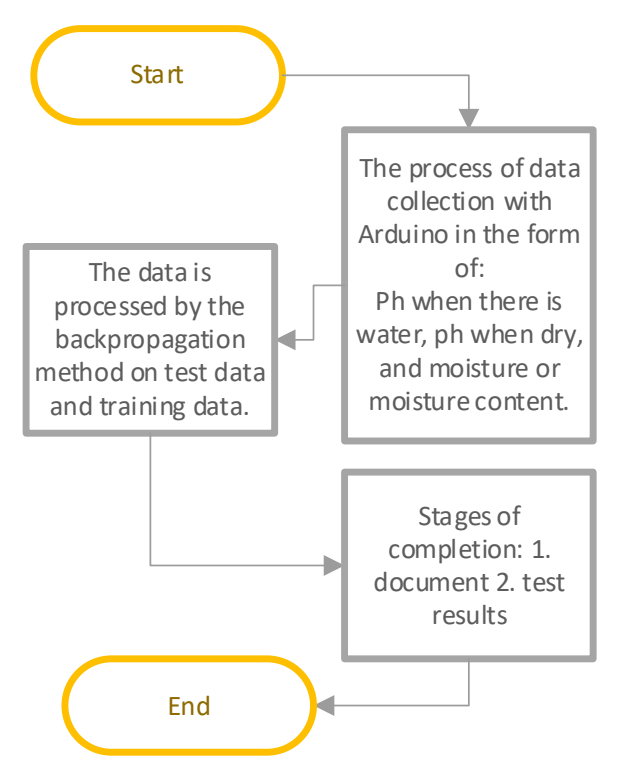

Fig. 1 General Process Flowchart

\section{RESULT}

In this study, testing was carried out from the results of the training data, getting results from 20 training data and getting about $60 \%$ results, which means getting 12 that is close to the prediction target. After that, the test results are carried out.

In the results of the test data from 10 that are following the objectives of the study, 8 data that match 2 data that are not suitable are shown in the following image.

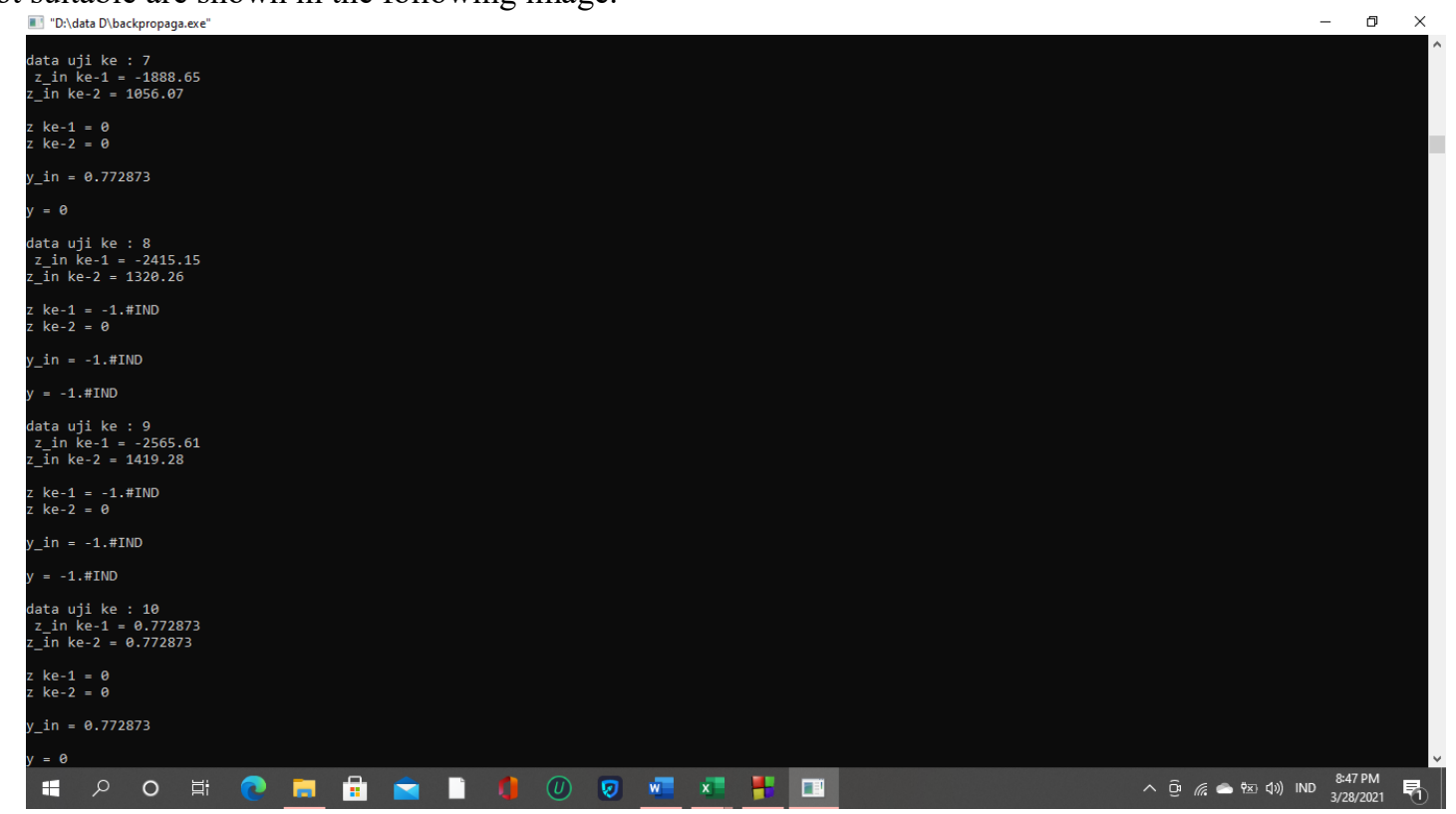

Fig. 2 Image of The Target Calculation Process 
Journal of Computer Networks, Architecture and High Performance Computing

Submitted : 18 April 2021

Volume 3, Number 2, July 2021

https://doi.org/10.47709/cnahpc.v3i2.950

Accepted : 27 April 2021

Published : 16 July 2021

\section{DISCUSSIONS}

In this study, the test was taken after the training data was processed by the backpropagation algorithm with the activation function. The results of the test were adjusted to several theories for soil fertility which were carried out with litmus paper to check whether they were accurate or not.

The test data is taken from 10 of the data that is owned, totaling 30 data taken from the soil near the river, potting soil, and soil close to the trees. The data were taken in the form of water content, soil ph when dry, and soil ph when alkaline. Data retrieval is taken by Arduino and algorithmic process in code block software. The following is the training data in table 1 , and the test data in table 2.

Table 1. Table on Training Data

\begin{tabular}{|c|c|c|c|c|}
\hline No & Soil Moisture & Ph When Dry & Ph When Wet & Target \\
\hline 1 & 30 & 6.66 & 6.7 & 0 \\
\hline 2 & 47 & 4.84 & 6.64 & -1 \\
\hline 3 & 42 & 2.86 & 6.69 & -1 \\
\hline 4 & 28 & 5.36 & 7.16 & 0 \\
\hline 5 & 57 & 5.71 & 6.88 & 0 \\
\hline 6 & 73 & 5.02 & 6.83 & 0 \\
\hline 7 & 38 & 8.21 & 6.39 & 1 \\
\hline 8 & 43 & 8.56 & 6.02 & 1 \\
\hline 9 & 50 & 7.18 & 5.89 & 0 \\
\hline 10 & 38 & 3.37 & 5.55 & -1 \\
\hline 11 & 42 & 5.02 & 5.48 & -1 \\
\hline 12 & 32 & 3.98 & 5.8 & -1 \\
\hline 13 & 54 & 4.15 & 6.44 & -1 \\
\hline 14 & 36 & 6.74 & 6.5 & 0 \\
\hline 15 & 45 & 7.35 & 6.63 & 0 \\
\hline 16 & 56 & 6.74 & 7.34 & 0 \\
\hline 17 & 50 & 5.45 & 6.77 & 0 \\
\hline 18 & 48 & 5.88 & 7.9 & 0 \\
\hline 19 & 60 & 4.41 & 7.05 & 0 \\
\hline 20 & 44 & 5.1 & 6.77 & 0 \\
\hline
\end{tabular}

Table 2. Table on Test Data Results

\begin{tabular}{cccc}
\hline No & Soil moisture & Ph when dry & Ph when wet \\
\hline 1 & 40 & 4.76 & 6.46 \\
\hline 2 & 38 & 4.5 & 4.79 \\
\hline 3 & 62 & 3.81 & 4.85 \\
\hline 4 & 54 & 3.63 & 4.71 \\
\hline
\end{tabular}


Journal of Computer Networks, Architecture and High Performance Computing

Submitted : 18 April 2021

Volume 3, Number 2, July 2021

https://doi.org/10.47709/cnahpc.v3i2.950

Accepted : 27 April 2021

Published : 16 July 2021

\begin{tabular}{cccc}
\hline 5 & 51 & 4.33 & 5.99 \\
\hline 6 & 77 & 4.24 & 5.99 \\
\hline 7 & 62 & 4.07 & 6.88 \\
\hline 8 & 33 & 3.72 & 5.37 \\
\hline 9 & 40 & 3.22 & 5.24 \\
\hline 10 & 42 & 3.29 & 4.99 \\
\hline
\end{tabular}

The whole process of the research stages is as follows:

1. Design stage. At this stage, the design is carried out for data collection and also for data retrieval. The tools used are Arduino, ADC sensor or sensor for $\mathrm{pH}$ when dry, soil moisture $\mathrm{V} 2$, and ph detection sensor which is used when alkaline

2. Implementation and testing phase. At this stage, the testing is carried out in code block software that uses the Backpropagation algorithm.

3. Stages of completion. At this stage, all the results of the training data and test data will be processed.

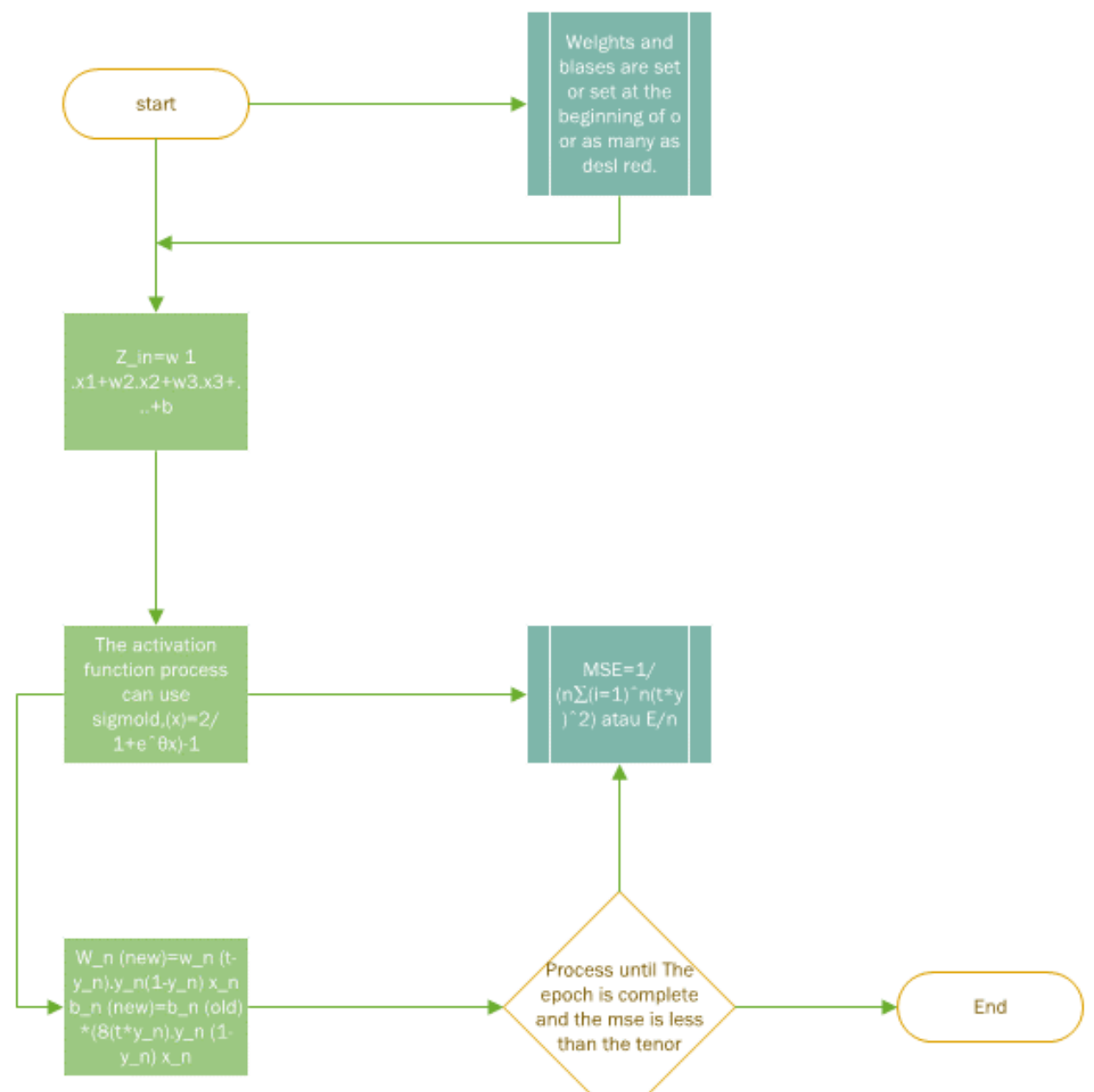

Fig. 3 Backpropagation Process 


\section{Journal of Computer Networks, Architecture and High Performance Computing}

Submitted : 18 April 2021

Volume 3, Number 2, July 2021

https://doi.org/10.47709/cnahpc.v3i2.950

Accepted : 27 April 2021

Published : 16 July 2021

\section{CONCLUSION}

In this study, conclusions from the process carried out from data collection to conducting the test phase with an artificial neural network algorithm or also known as ANN. The data collection at the place of the collection also affects the process of this network from the Arduino device itself, each sensor has a different data wave capture. This is done with litmus paper and ph paper. For backpropagation programming as well as during the experiment, many activations are used and some are suitable and some are not dependent on conditions, then in the second process and so on, the results of this research process are under discussion.

Bachtiar, A. M. (2017). C and C++ Programming . Bandung Informatics.

Darmawan, H. A. (2017). Arduino Fast Learning and Programming . Bandung.

Fadhel Akhmad Hizham, Yanuar Nurdiansyah, and Diksy Media Firmansyah. (2018). Implementasi of the Backpropagation Neural Network Method in the Student Graduation Timeliness Classification System.

Fajar, M. (2017). Easy to Learn ArduinMicrocontroller . Informatics Bandung.

Fani Widiastuti, Willis Kaswidjanti, Heru Cahya Rustamaji. (2014). Backpropagation Naural Network for Signature Recognition Applications.

Imelda Simolon, Asih Rohani, and Fikri Yatussaada, and Anjar Wanto. (2018). Application of the Backpropagation Algorithm in Predicting the Percentage of the Illiterate Population in Indonesia.

Kadir, A. (2018). Arduino and Sensors. Yogyakarta: Bandung.

Karamina, and Fikirinda W. H. (2017). The Complexity of Effect of Temperature and Soil Moisture on Soil Ph Value in Crystal Variety Guava Plantations.

Muhammad Dedek Yalidhan, and Muhammad Faisal Amin. (2018). Implementation of the Backpropagation Algorithm to predict Student Graduation.

Nordstrom D. K., Alpers C. N., Ptacek C. J., and Blowes D. W. (2000). Negative Ph and Extremely Acidic Mine Waters From Iron Mountain. California: Environmental Science and Technology.

Nugroho, Tri Cahyo, Oksana, and Evina Aryanti . (2013). Analysis of Chemical Properties of Peat Soil Converted Into Oil Palm Plantations in Kampar District.

Putri, Oktari Hermita, Sri Rahayu utami, and Syahrul Kurniawan. (2019). Soil Chemical Properties of Various land Uses in UBFOREST.

Tri Fadhel Prasetyo, Abghi Firas Isdianab, and Harun Sujadi. (2019). Implementasi of water Content Detection Devices in Internet Of Things Based Food Materials.

Wanto, A. (2018). Optimization of Predictions With Backpropagation Algorithm and Conjugate Gradient Beale Powell Restarts.

Wicaksono, M. F. (2019). Arduino App and Sensors. Informatics Bandung.

William Lambe T. and Robert V. (1969). Description of an Assemblage of Particles. 